\title{
A CONCEPTUAL REVIEW ON LINGUISTIC APPROACHES OF IDENTITY INVESTIGATION
}

\author{
Meinarni Susilowati
}

Email: meinarni_susilowati@yahoo.com

UIN Maulana Malik Ibrahim Malang

Alamat Korespondensi : Jl. Gajayana 50 Dinoyo Malang 65144

\begin{abstract}
Identity has been a blossoming issue in different fields. The intensity of investigating identity has stimulated the diverse methods and approaches to study identity from different angles. This paper discusses the how identity can be investigated from three different linguistic approaches, sociolinguistics, discourse analysis, and sociocultural linguistics approach. The practicality of these three approaches is explored to detect the nature of identity which is fluid, multiple, fragmented, socially, culturally, historically, religiously, and politically constructed and emerges within interactions. More space, however, is invested for elaborating the five principles of sociocultural linguistic approach due to its flexibility and multidimension of the approach. Empirical data is provided for proving its practicality for identity investigation. Further areas of investigation is given at the last part of the paper.
\end{abstract}

Keywords: identity, sociolinguistics, discourse analysis, sociocultural linguistics approach.

\section{INTRODUCTION}

Identity has been an intriguing issue in the last few decades. The discussion on identity is getting more apparently significant in this globalized era due to the issue of identity crisis faced by many countries. Globalization which stimulates uniformity requires its citizens to show their uniqueness. The projection of self shows how someone is different from others and how similarities can be shared among members of a community. Identity is projected, shared, negotiated to characterize the existence of someone. It becomes increasingly important to investigate identity due to complexity and its role in our global world (Kumaravadevelu, 2012). It is not uncommon to find many fields and disciplines which serve identity as their main menu of investigation. Identity has been extensively researched from psychological, anthropological, sociological and other perspectives. Within linguistic world, identity has also occupied a pertinent role which is studied from different angles. The pivotal relation between identity and linguistics indicates its critical role within any linguistic context (Nunan and Julie, 2010; Homberger and McKay, 2010; Fought, 2008; Benwell and Stokoe, 2006; Hall, 1997). The emergence of different approaches of identity investigation obviously shows promising significances of researching identity representation in various areas.

Identity now is no longer seen as the reflection of self which tends to be predetermined and permanent. Identity is characterized with some significant features which indicate its fluidity, multiplicity, fragmentation, and socially, culturally, religiously, politically context dependence (Susilowati, 2013). Within this concept, identity occurs only within interactions and has a language as the locus of its emergence. It is necessary to select suitable methods or approaches which are able to detect the appearance of identity with those features within the intended focus. This paper aims at elaborating three potential linguistic 
approaches of investigating identity representation. However, more emphasis is given to sociocultural linguistic approach due to its comprehensiveness and multidisciplinary nature in portraying identity representation.

\section{SOCIOLINGUISTICS}

The multi-dimension of identity embraces the branches of linguistics. The fact that identity owns language as the locus of its emergence provides spacious places for linguists to work on diverse approaches and methods depending on their focus. From a sociolinguistics perspective, identity concerns with "the ways in which people position or construct themselves and are positioned or constructed by other in socio cultural situations through the instrumentality of language and with reference to all of those variables that are identity markers for each society in the speech of its member" (Omoniyi and White, 2006, p. 1). It is further elaborated that, within this sociolinguistic boundary, identity owns particular features, namely (1) it is not fixed, (2) it is constructed within established contexts and may vary from one context to another, (3) it is a salient factor in every communicative context whether given prominence or not, (4) it informs social relationship and therefore also informs the communicative exchanges that characterize them, (5) it may be articulated in more than one in a given context in which case there will be a dynamic of identities management (p. 2). Within the sociolinguistics lens, identity is categorisable from variables which can be analogously correlated with behaviors, in this sense, language behaviors. These salient attributes in many ways fit the above nature of identity.

Sociolinguistic approach provides sensitivity in capturing identity representation within its cultural bound settings. This also signifies the importance of different social classes as the pool of data collection. Sociolinguistics has made variety of ways investigating identity, specifically by taking into account the different social identities. Within this framework, researching identity is done based on the assumption that "all social actions are separable into moments which make up the stretch of time it takes to accomplish them" and therefore people posses multiple identities depending on their multiple roles on their participation of the socio-cultural interactions (Omoniyi: 2006, p. 12). Each situation potentially provides 'multiple positioning acts' which evoke multiple identities with different degree of salience. It entails the visible role of identity category as a result of adjustment to the standard of appropriateness and suitable position which may flexibly fluctuate at all moments. A moment, in this sense, is 'a temporal unit of measurement and/or monitoring in the identification process" and "points in time in performance and perception at which verbal and non verbal communicative codes are deployed to flag up an image of self or perspectives of it" (Omoniyi, 2006, p. 21).

The above views lend voices to the methodological implications for investigating identity. Omoniyi (2006) proposes substantially practical ways of exploring identity from sociolinguistic perspectives. First of all, counting and setting out the numerical order in which several identities are foregrounded in the course of actions. Then, determine the identity in the section of spoken or written texts. All these identities are coded and presented in the entire situation but the section where identities were grounded needs illustration. These texts may suggest more than identity, depending on the function of different interpretive cultures. This can create a cluster of identities which requires a further deliberate explanation. Secondly, dividing action up on a timescale on to which identities are mapped to know what identities were foregrounded as well as which ones remain last longer periods. It is measured using a scale which starts from zero and is graded for the duration of talk delivery with marking to indicate (1) where a particular identity is first foregrounded, (2) what is displaced, or (3) backgrounded to give prominence to another. There could be a cluster of identities to a stretch of time on the scale. The last stage is showing by shading when two identities occupy the same moment.

Based on the above steps, Omoniyi (2006) explores practical applications of the whole stages on different types of data, both written or oral communication. However, the stages of detecting identity tend to roughly capture a 'bigger' picture which can only 
portray within particular setting of sociolinguistics. It is less sensitive in terms of catching particular linguistic features which may be attached by identity.

\section{DISCOURSE ANALYSIS}

Discourse analysis (DA) posits identity with its important portion. As DA basically concerns with 'who' as socially-situated person and 'what' as socially-situated activity, language use projects different identity on different situations (Gee, 2000). The 'who' is generally multiple even though it does not necessarily represent the producer of the utterance; metaphorical meanings and the reporters may substitute the original producers. Within this perspective, 'identity is actively, ongoingly, dynamically, constituted in discourse' (Benwell and Stokoe, 2006:4). Identity is also fragmentarily, contingently and crucially constituted in discourse and is shaped in discursive contexts. Paltridge (2006) includes context, occasion, and purpose of discourse which also contributes the identity emergence and specifically indicates the role of space and place of interactions as the important factors which determine one's identity. The occurrence of identity within interactions is then recognized by participant(s) of the interactions. Benwell and Stokoe (2006) portray identity from social constructive point of view which posits identity as a result of context constructions across a wide range of spoken and written communications. Diverse contexts of construction in which identity works includes some potential environments such as everyday conversations, institutional settings, narrative and stories, commodified contexts, spatial locations, and virtual environments. Seen within these contexts, discourse creates spacious places for identity. This involves the relation among discourse, interaction and identity as well as the reciprocal relation among discourse, ideology and identity.

Various approaches and methods of DA can be fruitfully employed for identity investigation. The eight discourse approaches proposed by Schiffrin (1994), for example, have been utilized as identity investigation with different focus suitable with the nature of the approaches. This includes speech acts, interactional sociolinguistics, conversation analysis, pragmatics, the ethnography of communication, and variation analysis. Within speech acts theory, for instance, identity can be detected from the locutionary, illocutionary and perlocutionary acts. Identity can be detected from the interlocutors' strategies of selecting particular locutionary acts under specific situations for delivering intended illocutionary acts with wished-for perlocutionary acts. Flexibility of an utterance reflected on its multiple response options offers spacious places for identity to forge. Conversation analysis sees identity as the self which is 'an oriented-to production and accomplishment of interaction' (Benwell and Stokoe, 2006, p. 36). The sequence of interactions may project highly complicated structure of identity negotiation due to the exchange of interpersonal needs establishes the positions of the interlocutors in the conversations. Turn-takings which occur in conversations do not only exchange the conversants' utterances for maintaining the smoothness of the communication but also show the how identity is negotiated, (re)constructed, and projected.

Critical discourse analysis (CDA) also plays a pertinent role in identity investigation. Its sensitivity in detecting power relation within interactions enables us to problematize how power domination, stereotyping, discrimination and abuse take place, even within a very casual daily interaction. Dolon and Todoli (2008) focus on how identity is constructed on three different areas, namely discursive construction of identity in educational contexts, building national and cultural identity, as well as identity construction and human suffering. Norton (2013) also has extensively researched social practice within educational settings with her concept of imagined identity. Wodak (2011) specifically list six primary areas of CDA investigation. This can be briefly stated as (1) analyzing the impact of Knowledge-based Economy (KBE) on various domains of a society, (2) integrating approaches from cognitive sciences into CDA, (3) investigating phenomenon within political system with the impact of media, transnational, global, and local development, (4) analyzing the impact of new media and genres which eventually creates new multimodal theories and approaches, (5) researching the relation between complex historical processes, 
hegemonic narratives and CDA approaches, and (6) integrating qualitative and quantitative methods and providing 'retroductable' analysis, self-reflective presentation of past or present processes.

The above discussion remarks the potential areas of identity investigation on a wide range of discourses. Further research are necessitated not only for providing more conclusive findings within certain areas but also entailing (new) approaches and methods for identity investigation within more up to date contexts.

\section{THE SOCIOCULTRAL LINGUISTIC APPROACH}

This discursive view of identity can be realized in two ways, namely "as discursive performance or construction of identity in interaction and as historical set of structures with regulatory power upon identity" (Benwell and Stokoe, 2006, p. 29). The involvement of power in this point relates the domain of authoritative voice and the individuals, which may be associated with inequality and discrimination. This creates a wider space for critical discourse analysis to explore identity. However, the tendency of involving immediate context for data analysis may prevent us looking at more closely some linguistic features which may significantly indicate identity representation. Therefore, I propose Bucholt and Hall's Sociocultural Approach as a more comprehensive tool in investigating identity representation.

The sociocultural linguistics approach sees identity as intersubjectively and interactionally constructed and therefore tends to be fluid, luminal, and interactionally constructed. This Bucholt and Hall's approach views identity by taking into account the details of linguistic features, and the existence of culture and society as well as involving diverse fields in viewing identity (2005). The interdisciplinary nature of this approach collectively acknowledges the available different ways of accommodating the emergence of identity. These are wrapped within five principles, namely emergence, positionality, indexicality, relationality and partialness.

The first principles, the emergence principle, is derived from the concept that identity emerges from the specific conditions of linguistic interaction. This is then formulated on the following tenet: Identity is best viewed as the emergent product rather than the pre-existing source of linguistic and other semiotic practices and therefore as fundamentally a social and cultural phenomenon (Bucholt and Hall, 2005). The principle can be easily figured out when someone's language does not conform with the social category to which she/he is normatively assigned. In this sense, identity occurs due to immediate trigger which requires her/him to expose particular identity.

The second principle, positionality principle, is derived from the micro details of identity because identity is constructed from moment to moment in interaction. This entails the concept that identity "encompasses (a) macro level demographic categories, (b) local ethnographically specific cultural positions, and (c) temporary and interactionally specific stances and participant roles" (Bucholtz and Hall, 2006, p. 592). This indicates that identity does not fall into broad social categories but is determined by formation of subjectivity and intersubjectivity in discourse. The interactional position someone temporarily stands on may accumulate sort of "ideological associations with both large-scale and local categories of identity" which may construct "who does what and how in interaction, though never in a deterministic fashion" (Bucholtz and Hall, 2005, p. 591). Particular a group of people may employ certain linguistic markers which apparently more recent appear on their conversations. Even though the conversants access quite similar linguistic resources, the markers may indicate more local dimension of their identity.

The third principle, indexicality principle, is based on the view of identity relations which "emerge in interaction through several related indexical processes including (a) overt mention of identity categories and labels, (b) implicatures and presuppositions regarding one's own or others' identity positions, (c) displayed evaluative and epistemic orientations to ongoing talk, as well as interactional footings and participation roles, and (d) the use of linguistic structures and systems that are ideologically associated with specific personas and groups" (Bucholtz and Hall, 2006, p. 594). 
Within this principle, indexicality is considered fundamental in portraying how linguistic forms are used to construct identity positions, not only for its dependency on interactional contexts for its meaning but also its link to social meaning. In a certain interaction, for instance, whitey does not merely refer to a fixed racial group but an intersubjectively negotiated identity category, which gives a clue to a reference of certain attitudes.

The fourth principle, relationality, indicates the importance of relational aspect in determining identity. Emphasizing this has twofold benefits; first, it glaringly shows that identity appears as a result of the social interaction which creates meaning in relation to other available identity positions and social status. Secondly, it goes beyond the view on identity which limit its scope based on sameness and difference because it offers much broader sense of seeing identity as 'intersubjectively constructed through several, often overlapping, complementary relations, including similarity/difference, genuineness/artifice, and authority/deligitimacy' (Bucholtz and Hall, 2005 , p. 598). The relationality principle entails four complementary identity relations, namely (1) adequation and distinction, (2) authentication and denaturalization, and (3) authorization and illegitimation.

The last principle, partialness, is as the consequence of proposing the fourth principle. As identity is relational, then, it will always be partial in the sense that it is produced through contextually situated and ideologically informed configurations of self and others. This generates the notion that "any given construction of identity may be in part deliberate and intentional, in part habitual and hence often less than fully consciousness, in part an outcome of interactional negotiation and contestation, in part an outcome of others' perceptions and representations, and in part an effect of larger ideological processes and material structures that may become relevant to interaction. It is therefore constantly shifting both as interaction unfolds and across discourse contexts" (Bucholtz and Hall, 2005, p. 606).

This principle attempts to capture the dynamic and multitude ways in which identity exceeds the individual self. To this point, it fits well with the nature of identity: fractured and discontinuous. This principle also poses the issue of agency, which is viewed as the completion of individual action.

When the above principles are confronted with a chunk of data, the appearance of identity can be detected. The following data are intentionally selected from the teachers' talks of an English as a foreign (EFL) contexts at a university in Indonesia. The situations may exclusively reflect uniqueness of an EFL setting but the analysis may trace different contexts. Therefore, the analysis can be transferred into different discourse. The excerpts below are cropped from the teacher's long explanation about "She was a chunky kid" in a literature class session. In this context, the teacher and the students were discussing with the word 'tan' which is found in a sentence in the story being discussed. It is closely related to the meaning of 'She was a chunky kid'.

(go on reading the text displayed on the screen). She was a chunky kid. Mr. Good's hands (0.2) the tan is (0.2) let's say thaaat a spot (0.2) usually called by a pigment. Usually $(0.2)$ white people have the hand (0.2) on the heat. And it interferes eer their skin (0.2) of the tan is more or less darker than the color of the skin and therefore they want to darken their skin by lying on the beach. (continue reading the text) With a good tan in a sweet broad soft looking can. I'm not to (0.2) you don't smile at all? (laugh)

From the above speech event, we can detect the teacher identity representation. The utterance "white people" in the above context can be perceived as identity through the indexicality principle. The utterance proceeds us to this principle from the use of linguistic structures and systems that are ideologically associated with specific personas and groups. In this sense, "white people" refers to the western people, who hold different culture. Mentioning the utterance "white people" clearly shows the teacher's way of assigning people based on particular group of people, whose culture is represented through certain color of their skin. The utterance "white people" is intentionally used to demonstrate teacher's view on a particular race without necessarily indicating any sense of discrimination or even stereotyping. Within 
this context, the teacher position "white people" equal to any other "colorful" races.

The second principle, emergence principle, can be utilized to portray the utterance "you don't smile at all?" which shows immediate response from the teacher who perceived less emotional involvement from the students concerning the value-laden concept of 'good tan' and 'a sweet broad soft looking can'. The utterance "you don't smile at all?" perfectly portrays the teacher's identity by attaching him to his local culture, which sees "a good tan in a sweet broad soft looking can" in different way from the white people.

The teacher mentions the term "white people" to refer to a group of native speakers of English. He does not perceive any other white people whose first language is not English as "white people". This is rooted from the context where teacher identity representation emerges which limits him to include the white who do not speak English or own English as the second language. In addition, the description of "tan" equips the students with another culture-laden term which shows the tendency of white people to darken their skin. Within the students' community, the similar tendency is also found. Some Indonesian people do efforts to make their skin brighter. This sameness facilitates them to understand the phenomenon of 'getting darkened' which is implied on the term "tan".
From the above analysis, it is shown that the approach potentially detects the occurrence of identity by exploiting more the linguistic aspects as well as sensitively capturing the cultural sense. The above data exhibits how a tiny linguistic features can be maximally used for marking identity representation. Some cultural contexts and markers may be effectively exploited as these may give a hint of identity. In this sense, the five principles lend a view of their practicality.

\section{CONCLUSIONS}

The discussion on the above three major methodological notions has mapped a potentially productive areas to investigate, namely identity representation. The emergence of different approaches obviously shows promising significances of identity investigation. Empirical data are required to show at least three points. Firstly, it is urgent to obtain the strengths and weaknesses of the methods in detecting the appearance of identity. Incarcerating more specific linguistic features which give significant clues for the emergence of identity is laudably needed. Secondly, particular subjects may require more specific method or approach for different nature of subjects may interact in different path. Thirdly, some other instruments are also recommended for accompanying a method or approach due to the uniqueness of data or contextual clues.

\section{REFERENCES}

Benwell, B.\& Stokoe, E. (2006). Discourse and Identity. Edinburgh; Edinburgh University Press.

Block, D. (2006). Identity in Applied Linguistics. In T.Omoniyi and G. White(Eds) The Sociolinguistics of Identity pp. 34-49. London: Continuum

Bucholt, M. \& Hall, K. (2005). Identity and Interaction: A Sociocultural Linguistic Approach. Discourse Studies, 7(4-5): 585-614

Dolon, R., and Todoli, J. (2008). Analyzing Identity in Discourse. Amsterdam: John Benjamin Pub. Co.

Fought, (2008). Language and ethnicity. New York: Cambridge University Press

Gee, J.P. (2000). An Introduction to Discourse Analysis. London: Rouletdge

Hall, S. (1997). Representation : Cultural Representation and Signifying Practices. Sage: London. 
Hornberger, N.H and McKay, S.L (Eds.) Sociolinguistics and Language Education. (pp. 89-115). Toronto: Multilingual Matters

Kumaravadevelu, B. (2012). Individual identity, Cultural Globalizationand Teaching English as an International Language. In Alsagoff, L., Renandya, W., Hu, Guangwei \& Mckay, S. (Eds). Teaching English as International Language: Principles and Practices. (pp.9-27). New York: Routledge

Norton, B. (2013). Identity and Language Learning: Extending the Conversation. Bristol: Multilingual Matters

Nunan, D. \& Choie, J. 2010. Language and Culture: Reflective Narrative and the Emergence of Identity. New York : Rouledge

Omoniyi, T. \& White, G. (2006). The Sociolinguistics of Identity. London: Continum.

Omoniyi, T. (2006). Hierarchy of Identity. In T.Omoniyi and G. White (Eds) The Sociolinguistics of Identity. pp 11-33. London: Continum.

Paltridge, . (2006). Discourse Analysis: An Introduction. London: Continuum

Schiffrin, D. (1994). Approaches to Discourse. Cambridge: Blackwell

Susilowati, M. (2013). Representation of Teachers' Identity within EFL Classroom Interactions. Unpublished dissertation. Universitas Negeri Malang

Wodak, R. (2011). Critical Discourse Analysis. In K.Hyland and B. Paltridge (Eds) Continuum Companion to Discourse Analysis. London: Continuum 